\title{
PRIMEIROS CONTORNOS DE UMA NOVA "CONFIGURAÇÃO PSÍQUICA"
}

\author{
Ana Maria Nicolaci-Da-Costa
}

\begin{abstract}
Uma tecnologia nova não acrescenta nem subtrai coisa alguma. Ela muda tudo. No ano de 1500 , cinqüenta anos depois da invenção da prensa tipográfica, nós não tínhamos a velha Europa mais a imprensa. Tínhamos uma Europa diferente.
\end{abstract}

(Neil Postman, 1998)

\begin{abstract}
RESUMO: Algumas tecnologias são consideradas revolucionárias na medida em que introduzem profundas alteraçóes tanto no tecido social quanto nas formas de pensar, agir, sentir e ser de seus contemporâneos. A internet é uma dessas tecnologias revolucionárias e, por isso mesmo, vem trazendo conseqüências que interessam de perto à psicologia. A principal delas é a emergência de uma nova "configuração psíquica”. Neste trabalho são apresentados vários estudos que, em conjunto, possibilitam a identificação de seus primeiros contornos.
\end{abstract}

Palavras-chave: Internet. Transformações sociais. Transformações subjetivas. Nova configuração psíquica.

\section{Preliminary CONTOURS OF A NeW "PSyChiC CONFIgURATION"}

ABSTRACT: Some technologies are considered revolutionary when they introduce profound changes both in the social tissue and in the way of being, thinking, feeling and acting of their contemporaries. The internet is one of these revolutionary technologies and, for this motive, it has been having consequences of close interest to the psychology. The principal of them is the emergence of a new "psychic configuration". This work presents various studies which, together make possible the identification of their preliminary contours.

Key words: Internet. Social changes. Subjective changes. New psychic configuration.

Doutora em psicologia e professora do Departamento de Psicologia da Pontifícia Universidade Católica do Rio de Janeiro (PUC-RIO).E-mail: anicol@mail.rdc.puc-rio.br 


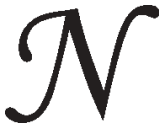

Na minha visão (Nicolaci-da-Costa, 2002a) e na de muitos outros autores (entre outros, Castells, 2000; Harvey, 1989; Lévy, 1990), há muitas semelhanças entre o que está acontecendo agora e aquilo que ocorreu na esteira de outras revoluçóes tecnológicas.

Dou um exemplo relativo à Revolução Industrial. A descoberta da primeira fonte de energia inanimada - o vapor -, no final do século XVIII, gerou profundas transformações na Europa do século XIX. Naquela época, a mecanização do trabalho, tornada possível pela nova fonte de energia, teve como efeito direto o aumento dramático da capacidade produtiva dos países industrializados. Este, no entanto, não foi o único efeito da nova descoberta. Ela teve vários e importantes efeitos indiretos: o surgimento dos grandes complexos urbano-industriais, a emergência de novas regras econômicas, sociais e políticas, a divisão entre locais e horários de trabalho e de lazer etc. $\mathrm{O}$ conjunto dessas mudanças acabou afetando a vida de todos (de maneira positiva ou negativa), não importa quem fossem ou onde estivessem.

De modo análogo, a internet vem trazendo profundos impactos em praticamente todos os setores da vida social e pessoal de milhões de pessoas ao redor do mundo, mesmo daquelas que jamais usaram um computador. $\mathrm{Na}$ realidade, os impactos da internet podem ser divididos em dois tipos principais - a) impactos diretos: aqueles gerados pela interação dos usuários com a rede de computadores ou pela interação entre usuários por meio dela; b) impactos indiretos: aqueles que incidem tanto sobre os usuários da rede quanto sobre homens e mulheres que podem jamais ter tido qualquer experiência direta com a internet. Isso porque tanto os primeiros quanto os últimos sofrem os efeitos das profundas alterações introduzidas pela internet no mercado de trabalho, na circulação do capital, no exercício da cidadania, no acesso à informação, na educação etc.

\section{Razões pelas quais mudanças sociais interessam à psicologia}

Há muito nos foi mostrado que aquilo que acontece no nível social tem um importante papel na construção da organização psíquica. No século XIX, por exemplo, o esfacelamento das comunidades feudais e a progressiva laicização das sociedades da época levaram ao desaparecimento de instâncias sociais - forçosamente externas - de vigilância e contro- 
le dos indivíduos. Tal desaparecimento, por sua vez, fez com que esses indivíduos, ao se livrarem das amarras dos costumes e da tradição, não mais pudessem recorrer a formas externas de contenção dos seus desejos.

O sociólogo francês Emile Durkheim (1897-1982) foi um dos primeiros a perceber que esse excesso de liberdade poderia se constituir em um sério problema. De seu ponto de vista, a nova organização social de seus dias era bem mais plural, permissiva e menos coesa que aquela que a havia antecedido. Essa pluralidade, permissividade e falta de coesão, por sua vez, faziam com que o desejo individual não mais pudesse ser eficazmente contido pelo todo social (que antes fazia uso de medidas punitivas e coercitivas com tal finalidade). A liberdade individual resultante desse novo estado de coisas podia parecer inebriante, mas freqüentemente tinha conseqüências bastante negativas. A principal delas era a perda de referenciais - a anomia -, cujo efeito era tão devastador a ponto de levar muitos ao suicídio.

Freud (1930-1980) fez registros análogos, embora de forma diferente. No contexto da progressiva liberdade individual gerada pela ausência de fontes externas de controle, observou que seus contemporâneos haviam sido forçados a erigir uma instância interna de controle e vigilância - o superego -, o que alterou substancialmente a estrutura e o funcionamento de seu psiquismo.

Durkheim e Freud não estavam sozinhos em suas observações e análises. A transformação subjetiva era evidente demais para passar despercebida por aqueles que desejavam compreender o que estava acontecendo com os homens e as mulheres da época.

Cabe a um outro sociólogo, no entanto, o mérito de colocar em palavras, de forma particularmente clara, como o social constrói o psicológico. Esse sociólogo é Simmel (1902-1987). Ao fazer uma comparação da vida numa metrópole com a vida na antiga ordem feudal, este lançava as bases para a compreensão do que é hoje conhecido como a construção social da subjetividade. Em "A metrópole e a vida mental", artigo que se tornou um clássico, ele mostrava como os diversos aspectos da vida social têm o poder de gerar alteraçôes na vida psíquica. Dizia:

(...) de cada ponto da superfície da experiência (...) pode-se deixar cair um fio de prumo para o interior da profundeza do psiquismo, de tal modo que todas as exterioridades mais banais da vida estão, em última análise, ligadas às decisôes concernentes ao significado e estilo de vida. 
Pontualidade, calculabilidade, exatidão, são introduzidas à força na vida pela complexidade e extensão da existência metropolitana e não estão apenas muito intimamente ligadas à sua economia do dinheiro e caráter intelectualístico. Tais traços também devem colorir o conteúdo da vida e favorecer a exclusão daqueles traços e impulsos irracionais, instintivos, soberanos que visam determinar o modo de vida de dentro, ao invés de receber a forma de vida geral precisamente esquematizada de fora. (Simmel, 1902, apud Velho, 1987, p. 15)

Como uma viagem ao passado e o recurso a análises sociológicas e filosóficas podem auxiliar na compreensão do presente psicológico

Quando estamos em meio ao turbilhão da mudança, é útil termos um contraponto que nos distancie da nossa percepção imediata, a qual, nesses momentos, tende a ser confusa e muitas vezes enganadora. São vários os autores - entre eles Castells (2000); Harvey (1989); Lévy (1990) - que têm recorrido às analogias entre o momento presente e os períodos que se seguiram à Revolução Industrial, ou à invenção da imprensa, com o fim de dar maior visibilidade às características do período em curso.

Em sua maioria, esses autores são sociólogos e filósofos que estão tentando ganhar distância para compreender as mudanças atuais. Suas análises, bem como aquelas realizadas pelos autores clássicos anteriormente citados, são de grande valor para quem quer que tente investigar as transformações internas pelas quais estão passando os homens e as mulheres contemporâneos (essas análises são freqüentemente utilizadas como ponto de partida para muitas investigações psicológicas). Isso porque, do momento que partimos do pressuposto de que o social (suas estruturas, instituiçóes, dinâmica, processos, tecnologias etc.) constrói o psicológico, temos que conhecer as características desse social para que possamos investigar suas conseqüências psicológicas.

Uma das principais manifestações de uma determinada sociedade (ou de um conjunto de sociedades), em uma dada época, é a tecnologia por ela desenvolvida e usada. A internet não é uma exceção a essa regra. Ela faz parte do conjunto de tecnologias (computadores, satélites, fibras ópticas, celulares etc.) que está tornando possível a emergência de uma nova "era" (por muitos chamada de pós-moderna, ver Bauman, 2001; Harvey, 1989; Sennett, 1998); uma era cujas principais características 
são a integração, a globalização, a relativização, o imediatismo, a agilidade, a derrubada de fronteiras, a extraterritorialidade, o nomadismo etc.

Ao fazer parte do conjunto de fatores que estão mudando a configuração social do mundo em que vivemos, a internet evidentemente também vem tendo um importante papel nas mudanças que estão ocorrendo nos nossos comportamentos, nas nossas formas de ver o mundo, bem como de nos vermos nele, e, acima de tudo, nas nossas formas de ser.

Investigar essas mudanças é o meu objetivo principal. Sem as compreender, não tenho dúvidas de que acabaremos por perder o acesso àqueles sobre os quais queremos atuar. Sem conhecermos as características da subjetividade contemporânea, corremos inclusive o risco de nos tornarmos inadequados ou, o que ainda é pior, preconceituosos (como é o caso daqueles para os quais qualquer mudança recebe valoração negativa a partir de parâmetros tradicionais).

\section{O que já se conhece desta nova subjetividade?}

Antes de dar uma resposta a esta questão, gostaria de fazer algumas observaçôes e ressalvas a respeito do que está envolvido na investigação dos contornos de uma nova organização subjetiva.

Conhecer uma nova organização subjetiva não é tarefa fácil nem rápida. Qualquer organização subjetiva é invisível e complexa o suficiente para demandar anos de observação paciente e pesquisa insistente. Explico por quê.

Dado que é invisível, uma organização subjetiva não pode ser observada diretamente (o que é observável é sempre o comportamento e não aquilo que está por trás dele). Por esta razão, temos que criar formas de a ela ganhar acesso. Isso significa dizer que devemos tentar identificar quais os melhores indicadores externos daquilo que se passa internamente.

Dado que é complexa, uma organização subjetiva não pode ser investigada como um todo. Deve ser investigada em etapas - com objetivos bem definidos embora parciais -, para que uma noção de conjunto possa eventualmente ser construída (não foi isso o que aconteceu com a organização subjetiva analisada por Freud?).

Feitas essas observações e ressalvas, creio que posso, finalmente, apresentar alguns resultados de pesquisas. Concentrarei minha exposição nos meus próprios resultados e naqueles de meus alunos. Em cada um 
dos trabalhos mencionados há, porém, referências a trabalhos realizados por outros pesquisadores. Uma revisão da literatura pode também ser encontrada em Leitão \& Nicolaci-da-Costa (2000).

Primeiros resultados: uma visão panorâmica das mudanças

Os primeiros resultados das minhas investigaçôes dos impactos subjetivos da internet sobre seus usuários brasileiros foram bastante abrangentes (Nicolaci-da-Costa, 1998). Esses resultados revelaram que, já em seus primeiros momentos, a internet estava gerando alteraçôes e subvertendo importantes expectativas em praticamente todas as áreas da experiência cotidiana de seus usuários.

Embora fazendo uso da internet há pouco tempo, esses usuários já haviam desenvolvido novos conceitos - como, por exemplo, os de ciberespaço, virtualidade, hipertexto, tempo real etc. -, a partir dos quais passavam a interpretar a nova realidade. Esses novos conceitos, por sua vez, introduziam alteraçōes substanciais em suas antigas concepções de espaço, realidade, escrita linear, tempo etc. e modificavam suas formas de pensar.

Era evidente que haviam também absorvido a nova lógica da rede. Uma lógica de excessos, agilidade, integração, relativização e expertise jovem. Uma vez absorvida, essa lógica era transportada para o mundo offline e produzia profundas alteraçōes também nos modos de agir e de ser desses sujeitos.

O mesmo acontecia com seus novos usos de linguagem - que incluíam a linguagem utilizada nos canais de chat e IRC e nos e-mails. Esses usos se caracterizavam por centenas, ou mesmo milhares, de novos vocábulos que penetravam o linguajar cotidiano fora da rede. Caracterizavam-se também por aquilo que chamei de estilo on-line de escrita, um estilo abreviado, econômico, objetivo e, acima de tudo, espontâneo (o que, conseqüentemente, gerava muitos pequenos e grandes erros ortográficos ou gramaticais). Embora adquiridos on-line, esses usos também cruzavam a fronteira entre o virtual e o real e passavam a influenciar os empregos de linguagem off-line.

No que diz respeito ao nevrálgico e sensível tópico dos novos relacionamentos, esse primeiro conjunto de resultados era ainda mais revelador. Apontava novas possibilidades para relacionamentos antigos 
(possibilidades essas que incrementavam a proximidade psicológica em relacionamentos geograficamente distantes); mostrava como os chats estavam subvertendo a forma de se travar contato com pessoas (conheciase o que diziam ser antes de conhecer-se suas características físicas); revelava que a escrita dos bate-papos e de outras formas de programas interativos estava se tornando uma nova e importante fonte de autoconhecimento e de auto-ajuda; e deixava claro o quanto podiam ser íntimos e duradouros os relacionamentos virtuais que subvertiam os procedimentos tradicionais de construção da intimidade e de possíveis parcerias de vida.

Em resumo, esses primeiros resultados revelavam um esboço do perfil de um sujeito - o homem ou a mulher do século XXI - que pensa, age, sente, faz uso da linguagem, relaciona-se com os outros e consigo mesmo de modos que são muito diferentes dos de seus predecessores.

Outros resultados: aprofundando a compreensão de diferentes aspectos da nova configuração subjetiva

\section{Pesquisas com usuários da internet}

A partir desses primeiros resultados, ficou claro que era necessário um conhecimento mais detalhado das características subjetivas contemporâneas cujo esboço acaba de ser delineado. Era também imprescindível travar contato com os possíveis conflitos - internos e/ou externos que a emergência dessas características está gerando ao entrar em choque com características e valores tradicionais certamente ainda presentes na sociedade como um todo e provavelmente em todos nós (pois toda mudança é lenta e geralmente parcial). Para tanto, vêm sendo realizadas diversas pesquisas com diferentes focos complementares.

A primeira a ser realizada foi uma pesquisa sobre o uso intensivo da internet. Falava-se muito sobre uma forma de "vício", mas raramente se tentava conhecer de perto os hábitos, as preferências e, particularmente, as opiniōes daqueles que utilizam a rede intensivamente. Diversas conclusões puderam ser tiradas com base nos resultados dessa pesquisa.

Em primeiro lugar, tais resultados mostraram como, a partir de relatos de estudos estrangeiros, o rótulo de "vício" é imposto pela mídia aos usuários "pesados" da internet. Tornaram também evidente que esse 
Primeiros contornos de uma nova "configuração psíquica"

rótulo era jocosamente descartado por todos os entrevistados como um vício "não maléfico", como um vício "saudável como a Coca-Cola" e outras qualificações congêneres (Nicolaci-da-Costa, 2002b). Em segundo lugar, mostraram que uma estranha e severa versão da ética do trabalho (tão rígida que parece saída de um tratado puritano) vem sendo absorvida por esses usuários a ponto destes avaliarem seu próprio uso prazeroso da internet como improdutivo, impróprio, incorreto, mau, etc. Em sua visão, somente o uso da Rede para fins de pesquisa (ou seja, de trabalho) é um uso produtivo, correto, próprio, qualificado, bom etc. (Nicolacida-Costa, 2002c). Por último, esses mesmos resultados deixaram claro que, longe de serem indefesos, esses usuários já erigiram formas de defesa da intimidade on-line. Essas formas de defesa fazem inclusive uso dos próprios recursos tecnológicos à disposição desses usuários, como, por exemplo, o de usar diferentes endereços de e-mail para separar diferentes círculos sociais com os quais eles mantêm relacionamentos em diferentes graus de intimidade (Nicolaci-da-Costa, 2003).

Um outro resultado bastante consistente refere-se ao poder da escrita na comunicação on-line. De fato, a comunicação por escrito, por intermédio de programas interativos sincrônicos (IRC, chats, ICQ e congêneres) e assincrônicos (e-mail), mostrou-se tão prazerosa, criativa e poderosa que serviu de base a quatro dissertaçóes de mestrado que tinham objetivos diferentes. Zaremba (2001) explorou as diferenças entre a escrita digital - o teclar - e a escrita à mão. Mostrou como a primeira é vista como mais prazerosa. Revelou também que os raciocínios empregados no teclar diferem bastante daqueles utilizados na escrita à mão. Costa (2001) mostrou que essa escrita prazerosa tem o poder de fazer com que as interações - muitas vezes anônimas - com desconhecidos transformem-se em relacionamentos virtuais intensos, solidários e duradouros nas salas de bate-papo do IRC. Romão-Dias (2001) investigou as personae assumidas por aqueles que participam de bate-papos digitais e, por meio dos depoimentos colhidos de vários usuários de programas interativos, pôde discutir as conseqüências psicológicas da multiplicidade dos perfis construídos por alguns usuários.

Prange (2003) trabalhou com uma outra forma de escrita (desta feita com características diferentes da escrita breve, econômica e objetiva dos e-mails e dos diálogos do ICQ e IRC), que parece ser fonte de grande prazer para muitos usuários da internet: a escrita dos blogs. Considerados diários on-line e criticados por expor a intimidade de seus autores, 
Prange revela que os blogs são um gênero híbrido de escrita de si, gênero este que submete a um constante processo de definição e redefinição as fronteiras entre as esferas do público e do privado. Isso porque os blogs conjugam - em diferentes proporções - as características comumente associadas a três diferentes gêneros de escrita de si: a) aquelas encontradas nos diários íntimos tradicionais; b) aquelas encontradas nas correspondências íntimas; c) aquelas da escrita de si destinada à publicação.

Além do prazer da escrita, os trabalhos de Costa, Romão-Dias e Prange têm um outro importante resultado em comum: o de que a escrita on-line é uma importante fonte de autoconhecimento. Segue-se o porquê.

Nessas três investigações, fica claro que a escrita on-line é, de uma forma ou de outra, geralmente usada para falar de si (não importa se o que é dito corresponde à "realidade" ou se é uma construção de personagens) em programas interativos. Quando o usuário está interagindo com diferentes interlocutores, esse falar de si - que, de fato, é um teclar sobre si - leva-o a ter diferentes retornos sobre o que diz. O próprio ato de escrever sobre si, agora acrescido da visão do outro ou de outros, forçosamente torna conscientes para o usuário os aspectos subjetivos sobre os quais ele e seus interlocutores discorrem.

O prazer de escrever, de interagir, de pesquisar, de viver on-line atravessa todas essas pesquisas. Esse mesmo prazer também pôde ser detectado, a partir de um ponto de vista diferente, em duas outras pesquisas, desta feita de maior fôlego (porque destinadas a servir de base a teses de doutorado). Nestas, o objetivo principal era o de investigar como terapeutas e profissionais de educação estavam vendo a penetração da internet em seus ambientes de trabalho. À sua discussão será reservada uma seção à parte.

\section{Pesquisas com profissionais que lidam com usuários da internet}

Leitão (2003) e Abreu (2003) buscaram avaliar os impactos indiretos da difusão da internet no Brasil. Para tanto, investigaram a fundo o que pensam e sentem dois grupos de profissionais que trabalham com usuários da rede (homens e mulheres - crianças, jovens ou adultos). Leitão, cuja formação é em psicologia, ouviu o que psicanalistas e gestalt-terapeutas tinham a dizer sobre os efeitos da rede em seus aten- 
dimentos. Abreu, que é pedagoga de formação, tinha objetivo análogo. Ao entrevistar professores dos ensinos fundamental e médio, queria identificar como estes estavam lidando com as transformaçôes decorrentes da penetração da internet nas escolas.

Em ambos os casos, os resultados obtidos podem ser divididos em dois conjuntos. O primeiro diz respeito às novas características subjetivas que estes profissionais (terapeutas e professores) percebem estar emergindo em crianças, jovens e adultos com os quais trabalham. Já o segundo conjunto se refere aos impactos que a internet vem tendo sobre os próprios profissionais, ou seja, diz respeito às reações e aos sentimentos dos próprios terapeutas e professores ante os efeitos diretos e indiretos da penetração da rede no cotidiano de seus clientes e alunos. Vejamos as contribuições de cada uma dessas pesquisas separadamente.

Leitão (2003) destaca que, da ótica dos terapeutas entrevistados, algumas características subjetivas dos pacientes-usuários da rede já são óbvias. São elas: o prazer que derivam do uso da internet, ${ }^{1}$ a sensação de "onipotência” que experimentam, as novas formas de se relacionarem com o corpo, as diferentes formas de excesso às quais se expóem e as novas formas de controle que adotam a partir do que a rede lhes coloca à disposição. Já no que se refere aos impactos indiretos sofridos pelos próprios terapeutas, a desorientação, o preconceito e as dúvidas com relação à eficácia de suas teorias e técnicas para a compreensão de seus atuais pacientes são alguns dos problemas com os quais esses profissionais estão se vendo confrontados.

Abreu (2003) também descreve alguns indicadores que, segundo os professores por ela entrevistados, apontam para transformações marcantes no aluno de hoje. Entre elas, destacam-se: sua familiaridade com o computador e com a internet (familiaridade que supera em muito a dos professores e gera uma inversão da hierarquia de saber/poder), sua exposição ao excesso de informação, sua dispersão, seu desinteresse pelas aulas tradicionais, seu raciocínio ágil, sua incapacidade de concentração e aprofundamento. Para Abreu, é, no entanto, o prazer que os alunos derivam do ambiente da internet que se revela uma das principais fontes de indagação e surpresa para os professores entrevistados. Usuários comedidos da rede, esses professores se mostram ameaçados e ansiosos diante das mudanças radicais que a rede está impondo à pedagogia tradicional. Isso porque, entre outros fatores, têm menos familiaridade com 
as novas tecnologias do que os alunos, sobre ela sabem menos do que estes e, por isso mesmo, temem se tornar obsoletos.

Quais as características do sujeito contemporâneo a partir de todos esses resultados?

A internet é um espaço de vida alternativo, no qual a escrita é o meio privilegiado de comunicação e de experimentação de novas formas de ser. O sujeito contemporâneo escreve - ou melhor, tecla - para se comunicar, escreve para construir personagens, escreve para informar, escreve para construir relacionamentos, escreve para registrar pensamentos, escreve para dar sentido às suas experiências múltiplas e diversificadas etc.

Escreve artigos, escreve textos para sites, escreve e-mails, escreve blogs, dialoga por escrito e em tempo real com vários interlocutores, constrói personagens... Escreve anonimamente, assina o que escreve, assina o que não escreveu, escreve em sua própria língua e em outras (muitas vezes aprendidas e/ou praticadas on-line).

Lê muito também. Grande parte da informação que circula no mundo é absorvida por seus olhos. A contemporaneidade é a era da escrita (e, conseqüentemente, da leitura).

O contato direto com as características da internet - sua organização em rede, seus hipertextos e links, sua comunicação predominantemente escrita, sua agilidade, seu imediatismo, seus excessos, suas possibilidades de integração de coisas dispersas, o acesso a mundos diversos que ela possibilita, as interações anônimas que faculta - tem efeitos que transpóem os limites do virtual e penetram a realidade off-line. Esse contato e essa transposição geram um perfil de sujeito que parece ser característico do século XXI. Vejamos.

1) Um sujeito que sente prazer em praticamente tudo o que faz on-line.

2) Um sujeito que está disposto a experimentar novas formas de ser.

3) Um sujeito multitarefa, que faz diversas coisas ao mesmo tempo.

4) Um sujeito que é ágil e está em constante movimento (mesmo quando seu corpo está imóvel). 
5) Um sujeito que, por meio de sua escrita e não de seu corpo, habita vários espaços (muitas vezes simultaneamente). Nesses espaços - como, por exemplo, os de programas interativos online como o ICQ, o IRC, e os blogs - ganha acesso a diferentes realidades (culturais, imaginárias, sociais etc.).

6) Um sujeito que, nesses espaços, pode se apresentar com identidades e características diferenciadas, ou seja, pode construir diferentes narrativas (verídicas ou não, sinceras ou não, anônimas ou não) a respeito de si mesmo.

7) Um sujeito que ganha conhecimento sobre si mesmo e sua singularidade na medida em que escreve sobre si e tem retorno sobre essa escrita.

8) Um sujeito que, em decorrência do retorno que recebe a partir do que escreve sobre si, submete as definiçóes de si a um constante processo de revisão.

9) Um sujeito que, por se expor a tantos espaços, realidades, experiências e retornos, tem a si mesmo como a única fonte de integração possível dos resultados dessas múltiplas exposições e desses múltiplos retornos.

10) Um sujeito que, em conseqüência dessas múltiplas exposições, desses múltiplos retornos e das integrações possíveis, submete a um constante processo de definição e redefinição as fronteiras entre as esferas do público e do privado (para a defesa das quais cria novas formas e lança mão de novos recursos).

11) Um sujeito que está tendo dificuldades para encontrar fórmulas com que se proteger dos excessos gerados por sua constante mobilidade e exposição à diversidade.

12) Um sujeito que, por efetuar, ele próprio, um recorte nas realidades às quais está exposto, torna-se cada vez mais singular e auto-referido.

13) Um sujeito que é flexível, adaptável, inquieto e ávido de novas experiências.

14) Um sujeito que conhece poucos limites para seus desejos. 


\section{Conclusão}

Como foi mencionado no início deste trabalho, as mudanças ocorridas na esteira da Revolução Industrial fizeram com que o tecido social feudal (comunitário) se esgarçasse e, em conseqüência, os homens e as mulheres daquela época ganhassem uma grande sensação de liberdade e, ao mesmo tempo, se sentissem desorientados - ao perderem suas amarras sociais (principalmente aquelas que continham os seus desejos individuais). Isso, no entanto, foi passageiro, na medida em que outras amarras, tanto internas (como, por exemplo, o superego) quanto externas (como as várias formas de regulação da vida nas novas sociedades) foram erigidas ao longo dos séculos XIX e XX.

Algo semelhante está ocorrendo agora, nesta passagem de século e de milênio, em decorrência dos impactos diretos e/ou indiretos gerados pela difusão das novas redes digitais, principalmente da internet. Nós mesmos e nossos contemporâneos estamos perdendo nossas antigas formas de nos organizarmos, tanto externa quanto internamente. Os sólidos referenciais do período moderno, que até pouco tempo refreavam nossos desejos e serviam de âncoras para a nossa organização psíquica, estão deixando de existir e novos referenciais estão ainda em construção. Estamos, portanto, novamente enfrentando um período de muita sensação de liberdade e, também, de muita desorientação e muita experimentação. O importante é que reconheçamos que, de todo este processo de mudança, está emergindo um sujeito bem diferente daquele do indivíduo moderno, estudado pelas teorias psicológicas dos séculos XIX e XX. Um sujeito cuja "configuração psíquica" a psicologia tem por obrigação estudar e compreender. A série de pesquisas apresentadas neste artigo permite identificar os primeiros contornos do seu perfil. Há, no entanto, ainda muito por fazer.

Recebido em fevereiro de 2004 e aprovado em março de 2004.

\section{Nota}

1. Prazer esse que assusta os terapeutas entrevistados, dado que estes somente fazem uso da rede com finalidades de trabalho. 


\section{Referências bibliográficas}

ABREU, R. A internet na prática pedagógica: novos desafios e conflitos para os educadores. 2003. Tese (Doutorado) - Curso de Pós-Graduação em Psicologia Clínica, Pontifícia Universidade Católica do Rio de Janeiro, Rio de Janeiro.

BAUMAN, Z. Modernidade líquida. Rio de Janeiro: Jorge Zahar, 2001. CASTELLS, M. A sociedade em rede. São Paulo: Paz \& Terra, 2000.

COSTA, A.C.A. IRC: uma nova alternativa para as relações entre as pessoas. 2001. Dissertação (Mestrado) - Curso de Pós-Graduação em Psicologia Clínica, Pontifícia Universidade Católica do Rio de Janeiro, Rio de Janeiro.

DURKHEIM, E. O suicídio: um estudo sociológico. Rio de Janeiro: Zahar, 1982. (Original publicado em 1897)

FREUD, S. O mal-estar na civilização. In: FreUd, S. Obras completas de Sigmund Freud. Rio de Janeiro: Imago, 1980. v. 21. (Original publicado em 1930)

HARVEY, D. Condição pós-moderna. São Paulo: Loyola, 1989.

LEITÃO, C. Impactos subjetivos da internet: reflexōes teóricas e clínicas. 2003. Tese (Doutorado) - Curso de Pós-Graduação em Psicologia Clínica, Pontifícia Universidade Católica do Rio de Janeiro, Rio de Janeiro.

LEITÃO, C.; NICOLACI-DA-COSTA, A.M. Psicologia clínica e informática: por que essa inusitada aproximação? Psicologia clínica, Rio de Janeiro,v. 12, n. 2, p. 189-205, 2000.

LÉVY, P. As tecnologias da inteligência: o futuro do pensamento na era da informática. Rio de Janeiro: Editora 34, 1990.

NICOLACI-DA-COSTA, A.M. Na malha da rede: os impactos íntimos da internet. Rio de Janeiro: Campus, 1998.

NICOLACI-DA-COSTA, A.M. Revoluçōes tecnológicas e transformaçōes subjetivas. Psicologia: teoria e pesquisa, Brasília, DF, v.18, n. 2, p. 193-202, 2002a. 
NICOLACI-DA-COSTA, A.M. Internet: a negatividade do discurso da mídia versus a positividade da experiência pessoal. À qual dar crédito? Estudos de Psicologia, Natal, v. 7, n. 1, p. 25-35, $2002 \mathrm{~b}$.

NICOLACI-DA-COSTA, A.M. Quem disse que é proibido ter prazer online: identificando o positivo no quadro de mudanças atual. Psicologia: ciência e profissão, Brasília, DF, v. 22, n. 2, p. 12-21, 2002c.

NICOLACI-DA-COSTA, A.M. Ciberespaço: nova realidade, novos perigos, novas formas de defesa. Psicologia: ciência e profissão, Brasília, DF, v. 23, n. 2, p. 66-75, 2003.

PRANGE, A.P.L. Da literatura aos blogs: um passeio pelo território da escrita de si. 2003. Dissertação (Mestrado) - Curso de Pós-Graduação em Psicologia Clínica, Pontifícia Universidade Católica do Rio de Janeiro, Rio de Janeiro.

POSTMAN, N. Five things we need to know about technological change. 1998. Disponível em: <http://itrs.scu.edu/tshanks/pages/Comm12/ 12Postman.htm>. Acesso em: 9 fev. 2004.

ROMÃO-DIAS, D. Nossa plural realidade: um estudo sobre a subjetividade na era da internet. 2001. Dissertação (Mestrado) - Curso de Pós-Graduação em Psicologia Clínica, Pontifícia Universidade Católica do Rio de Janeiro, Rio de Janeiro.

SENNETT, R. A corrosão do caráter: conseqüências pessoais do trabalho no novo capitalismo. Rio de Janeiro: Record, 1998.

SIMMEL, G. A metrópole e a vida mental. In: Velho, O.G. (Org.). O fenômeno urbano. Rio de Janeiro: Guanabara, 1987. p. 11-25. (Original publicado em 1902)

ZAREMBA, R. Escrevendo (ou seria "teclando"?!) o homem do século XXI. 2001. Dissertação (Mestrado) - Curso de Pós-Graduação em Psicologia Clínica, Pontifícia Universidade Católica do Rio de Janeiro, Rio de Janeiro. 